\title{
Doenças Sexualmente Transmissiveis em Mulheres em Idade Fértil: um Estudo Populacional
}

\section{Sexually Transmitted Diseases in Women of Reproductive Age: a Population-based Study}

Autora: Fabíola Araújo Sales de Oliveira

Orientadora: Profa. Dra. Lígia Regina Sansigolo Kerr-Pontes

Dissertação de Mestrado apresentada ao Departamento de Saúde Comunitária da Faculdade de Medicina da Universidade Federal do Ceará, em 14 de maio de 2004.

Objetivo: acessar a prevalência de DST e fatores de risco (FR) em mulheres em idade fértil de um município do interior do Nordeste.

Métodos: estudo transversal baseado na aplicação de questionário, exame ginecológico e diagnóstico laboratorial para sífilis (VDRL/FTA-Abs), clamidíase, gonorréia (ambos LCR), HPV (PCR), tricomoníase (exame direto/Papanicolaou) e HIV (ELISA) em mulheres entre 12 e 49 anos do município de Pacoti, Ceará.

Resultados: participaram 592 mulheres. As taxas de prevalência encontradas foram: sífilis 0,2\% (IC95\%: 0,01,1), clamidiase 4,5\% (IC95\%: 3,0-6,6), gonorréia 1,2\% (IC95\%: 0,5-2,6), HPV 11,7\% (IC95\%: 9,3-14,7), tricomoníase 4,1\% (IC95\%: 2,7-6,1) e pelo menos uma DST 19,6\% (IC95\%: 16,5-23,2). Não houve HIV positivo. Ter realizado exame preventivo anterior foi fator protetor $(\mathrm{OR}=0,36$; IC95\%: 0,21-0,62). Foram identifi- cados os seguintes FR: $\geq 3$ parceiros na vida $(\mathrm{OR}=2,79$; IC95\%: 1,78-4,39), primeira gestação $\leq 16$ anos (OR = 2,14; IC95\%: 1,13-4,06), não saber se parceiro tem outra parceira (OR = 1,68; IC95\%: 1,00-2,81), idade $\leq 19$ anos (OR = 1,9; IC95\%: 1,08-3,36), $\geq 2$ parceiros nos últimos 12 meses (OR = 3,01, IC95\%: 1,36-6,68), início da vida sexual $\leq 16$ anos $(\mathrm{OR}=1,99$; IC95\%: 1,28-3,12) e não habitar com o parceiro (OR = 1,73; IC95\%: 1,10-2,70). $\mathrm{O}$ fator protetor e os primeiros três FR acima foram independentemente associados a DST no modelo multivariado.

Conclusões: as DST representam um importante problema na população estudada. O presente estudo permite inferir sobre a epidemiologia das DST em outros municípios de perfil semelhante.

PALAVRAS-CHAVE: DST. Rastreamento. AIDS.

Farmacocinética eAnálise da Distribuição Transplacentária da Fentanila naAssistência Anestésica via Epidural de Gestantes Normais

\section{Pharmacokinetics and Analysis of Transplacental Distribution of Fentanyl in Epidural Anesthesia for Normal Pregnant Women}

Autora: Elaine Christine Dantas Moisés

Orientador: Prof. Dr. Sérgio Pereira da Cunha

Dissertação de Mestrado apresentada à Faculdade de Medicina de Ribeirão Preto - Universidade de São Paulo Departamento de Ginecologia e Obstetrícia, em 23 de julho de 2004.

Introdução: os procedimentos anestésicos em obstetrícia persistem como desafio para obstetras e anestesistas que prosseguem na investigação de métodos seguros e eficazes de analgesia e anestesia, possibilitando os melhores resultados obstétricos e perinatais, aliados a conforto e segurança. No parto por via abdominal, o bloqueio epidural representa um dos procedimentos anestésicos mais freqüentes em obstetrícia. A fentanila é um fármaco opióide largamente utilizado como coadjuvante nessa prática, fato que justifica o estudo farmacocinético do mesmo nessas condições.

Objetivos: investigar a farmacocinética e a transferência placentária da fentanila em parturientes cujas gestações foram resolvidas por via abdominal, com anestesia epidural.

Casuística e Métodos: foram avaliadas 10 parturien- tes com gestação a termo, consideradas normais clinicamente e laboratorialmente. Todas as gestantes receberam $5 \mathrm{~mL}$ de cloridrato de lidocaína a $2 \%$ sem vasoconstrictor para bloqueio de pele e subcutâneo, seguido de injeção epidural de $2 \mathrm{~mL}$ de citrato de fentanila a $0,05 \mathrm{mg} / \mathrm{mL}, 15 \mathrm{~mL}$ de cloridrato de bupivacaína $0,5 \%$ com epinefrina $1: 200000$ e $10 \mathrm{~mL}$ de cloridrato de lidocaína a $2 \%$ sem vasoconstrictor. Na seqüência, foram coletadas amostras sangüíneas maternas nos tempos $1,5,15,30,45,60,120,240$, $360,480,600,720$ e 840 minutos e amostras de sangue do cordão umbilical para determinação das concentrações de fentanila por cromatografia. Determinadas as concentrações, foram traçadas as curvas de concentração em função do tempo e análise farmacocinética bicompartimental ou tricompartimental para a fentanila, determinando-se $\mathrm{t} 1 / 2$ de $\alpha$, 